\title{
AKURASI SKOR RISIKO KILLIP SEBAGAI PREDIKTOR PROGNOSIS PASIEN SINDROM KORONER AKUT ST-ELEVATION MYOCARD INFARCTION
}

\author{
Ratna Roesardhyati, Titin Andri Wihastuti, Tina Handayani Nasution \\ Magister Keperawatan Fakultas Kedokteran Universitas Brawijaya Malang \\ Jl. Veteran Malang Jawa Timur \\ Email : ratnaroes@gmail.com
}

\begin{abstract}
Acute Coronary Syndrome (ACS) with ST-ELevation Myocard Infarction (STEMI) is the leading cause of morbidity and mortality worldwide, especially in developed countries. Many risk factors in ACS patients require long treatment and focused treatment. Stratification of risks plays an important role in assisting prediction of clinical outcomes or as a prognosis in patients with ACS. The prognosis of STEMI patients is indicated by Length of Stay (LOS) which is the number of days of STEMI patient care at ICCU. Currently there is risk score used as predictors in SKA with STEMI, some of which is Killip. This riset to analyze accuracy of Killip risk score with prognosis (LOS) STEMI patient in ICCU dr. Iskak Tulungagung. The research design used was analytic observational research with retrospective cohort approach. The location of this study was in RSUD dr. Iskak Tulungagung. The number of medical record were 125 taken by using purposive sampling technique. Data was analyzed using Spearman test. The result of Spearman test showed that Killip showed a significant association with STEMI patient's LOS in ICCU $(p=0.003)$ with coefficient correlation $r=0.260$. The conclusion in this study was that Killip had a significant relationship with the prognosis (LOS) of STEMI patients in ICCU.
\end{abstract}

Keyword : ST-Elevation Myocard Infarction, Killip, Length of Stay

Abstract : Sindrom Koroner Akut (SKA) dengan ST-Elevation Myocard Infarction (STEMI)merupakan penyebab utama morbiditas dan mortalitas di seluruh dunia, terutama di negara-negara maju. Faktor risiko yang begitu banyak pada pasien SKA membutuhkan perawatan yang lama dan pengobatan yang terfokus. Stratifikasi risiko tersebut berperan penting dalam membantu prediksi luaran klinis atau sebagai prognosis pada pasien SKA. Prognosis pasien STEMI ditunjukkan dengan Length of Stay (LOS) yang merupakan jumlah hari lama rawat pasien STEMI di ICCU. Saat ini terdapat skor risiko yang digunakan sebagai prediktor pada SKA dengan STEMI, yaituKillip. Tujuan penelitian ini untuk mengalisis akurasi skor risiko Killip dengan prognosis (LOS) pasien STEMI di ICCU RSUD dr. Iskak Tulungagung. Desain penelitian yang digunakan adalah penelitian observasional analitik dengan pendekatan kohort retrospektif. Lokasi penelitian di Intalasi Rekam Medis RSUD dr. Iskak Tulungagung. Jumlah rekam medis sebanyak 125 yang diambil dengan teknik purposive sampling. Analisa data menggunakan uji Spearman. Hasil uji Spearman menunjukkan bahwa Killip menunjukkan hubungan yang signifikan dengan LOS pasien STEMI di ICCU $(p=0.003)$ dengan besar korelasi $r=0.260$. Kesimpulan dalam penelitian ini adalah skor risiko Killip memiliki hubungan signifikan dengan prognosis (LOS) pasien STEMI di ICCU.

Kata Kunci : ST-Elevation Myocard Infarction, Killip, Length of Stay

\section{PENDAHULUAN}

Sindrom Koroner Akut (SKA) merupakan penyebab kematian tertinggi pada pria ataupun wanita di seluruh dunia (Kinnaird et al., 2013). Kematian akibat penyakit kardiovaskulardi Amerika Serikat yaitu sebesar $35,3 \%$ atau sebanyak 864.500 kasus, sedangkan kematian akibat SKA yaitu sebanyak 151.000 kasus pada tahun 2005. Sindrom Koroner Akut dengan ST-Elevation Myocard Infarction (STEMI) merupakan penyebab utama morbiditas dan mortalitas di seluruh dunia, terutama di negara-negara maju (Stiermaier et al., 2013). MenurutWorld Health Organization (WHO) pada 'Noncommunicable Diseases (NCD) Country Profiles 2014' di tahun 2013 dilaporkan bahwa penyakit kardiovaskular merupakan penyebab kematian tertinggi di Indonesia, yaitu sebesar $37 \%$ dari keseluruhan angka kematian. Prevalensi SKA dengan STEMI di Indonesia meningkat dari $25 \%$ ke 40\% (Kemenkes, 2013).

Pasien SKA dengan STEMI mengalami oklusi total pada arteri koroner dengan dampak iskemia hingga infark jaringan miokard (Hector et al., 2011). Hal tersebut menyebabkan pasien memiliki angka kematian yang tinggi, khususnya dalam 2 jam pertama setelah onset serangan. Faktor risiko yang begitu banyak pada pasien SKA membutuhkan perawatan yang lama dan pengobatan yang terfokus (Morrow et al., 2000). Prognosis dengan melihat skor risiko merupakan salah satu pertimbangan dalam 
mengoptimalkan penanganan pasien SKA (Fox et al., 2002).

Saat ini terdapatskor risiko Killip yang digunakan untuk memprediksi prognosis tersebut. Skor Killip dilakukan berdasarkan stratifikasi hasil pemeriksaan fisik pasien SKA dengan STEMI. Digunakan untuk mengidentifikasi risiko tertinggi kematian dan manfaat potensial dari perawatan dalam ruangan cardio care (Killip, 1967). Pada Killip, pengklasifikasian yang dilakukan berdasarkan derajat gagal jantung saja, tanpa melihat komponen stratifikasi lainnya (Killip, 1967). Killip hanya dapat memprediksi penurunan klinis hingga 30 hari (Wickramatilake et al., 2015). Derajat keparahan memberikan dampak terhadap lama perawatan atau Length of Stay (LOS) pada pasien STEMI (Barakaung et al., 2013).

Berdasar uraian diatas, peneliti bermaksud melakukan penelitian untuk mengetahui lebih lanjut mengenai akurasi skor risiko Killip sebagai prediktor prognosis pada pasien SKA dengan STEMI di Ruang ICCU RSUD Dr. Iskak Tulungagung. Dengan mengetahui hasil akurasi Killip sebagai prediktor prognosis pada pasien STEMI, peneliti dapat sedini mungkin mengidentifikasi pasien yang berisiko tinggi untuk memberikan perawatan dan pengobatan yang optimal.

\section{METODE PENELITIAN}

Desain penelitian yang digunakan adalah penelitian observasional analitik dengan pendekatan kohort retrospektif. Penelitian ini dilakukan di RSUD dr. Iskak Tulungagung. Jumlah sampel adalah 125 rekam medis yang ditentukan dengan teknik purposive sampling. Kriteria inklusi dalam penelitian ini terdiri dari (1) Rekam medis pasien di ICCU yang terdiagnosa SKA dengan STEMI oleh dokter dikarenakan adanya ST-elevasi berdasarkan AHA (2013); (2) Data rekam medis lengkap. Alat yang digunakan dalam penelitian ini ialah lembar observasi Killip. Pengambilan data dilakukan dengan melakukan pencatatan dari data sekunder. Data diambil dengan menggunakan lembar observasi untuk Killip berdasarkan data rekam medis. Data yang telah terkumpul selanjutnya dianalisis menggunakan analisis univariat dan analisis bivariat.

Analisis univariat digunakan untuk mengetahui data karakteristik responden (meliputi usia dan jenis kelamin) dan data parameter variabel penelitian. Analisis bivariat yang digunakan untuk mengetahui perbedaan korelasi ialah uji Spearman dikarenakan data Killip tidak berdistribusi normal. Persetujuan etik dengan memperhatikan respect for person, benefence \& non maleficence dan justice.

\section{HASIL PENELITIAN}

Berdasarkan Distribusi Frekuensi Karakteristik Responden di ICCU RSUD Dr. Iskak Tulungagung didapatkan bahwa sebagian besar responden berjenis kelamin laki-laki yaitu sebanyak 103 responden (82.4\%) dan sebanyak 22 responden adalah wanita $(17.6 \%)$. Karakteristik usia responden menunjukkan hasil seimbang pada kategori usia pertengahan (41-60 tahun) sebanyak 62 $(49.6 \%)$ responden dan usia lanjut sebanyak 61 responden $(48.8 \%)$, sisanya usia dewasa $1.6 \%$.

Berdasarkan Hasil Distribusi Frekuensi Karakteristik Responden berdasarkan kelas Killip didapatkan bahwa sebagian besar responden berada dalam kelas Killip I yaitu sebesar 87 responden (69.6\%), sedangkan jumlah responden dengan kelas Killip III memiliki jumlah paling sedikit yaitu 5 responden (4\%).

Berdasarkan Distribusi Frekuensi Responden berdasarkan Length of Stay didapatkan bahwa Length of Stay responden di ICCU sebagian besar dalam kategori "short" ( $\leq 3$ hari) sebesar 58 responden (46.4\%), sedangkan Length of Stay responden di ICCU paling sedikit dalam kategori "long" ( $>5$ hari) sejumlah 26 responden (20.8\%).

\section{Analisa Bivariat}

Tabel Hasil Uji Korelasi Spearman's rho

\begin{tabular}{lccc}
\hline & \multicolumn{3}{c}{ Length of Stay (LOS) } \\
\cline { 2 - 4 } & $\mathrm{n}$ & $\mathrm{r}$ & $p$-value \\
\hline Skor Killip & 125 & 0.260 & 0.003 \\
\hline
\end{tabular}

Sumber : Data Primer 2017.

Berdasarkan tabel menunjukkan bahwa skor Killip memiliki nilai signifikansi ( $p$-value) yaitu 0.003 . Hal ini berarti terdapat hubungan signifikan secara statistik $(p<0.05)$. Koefisien korelasi (r) 0.260 menunjukkan bahwa kekuatan korelasi skor Killip dengan LOS adalah rendah. 


\section{PEMBAHASAN}

Berdasarkan hasil uji analisa statistik dalam penelitian ini menunjukkan bahwa terdapat korelasi yang bermakna $(p=0.003)$ antara Killip dengan LOS pasien STEMI dan besar koefisien korelasi (r) 0.260. Koefisien korelasi menunjukkan korelasi positif yang berarti semakin tinggi Killip maka LOS akan semakin panjang, begitu pula sebaliknya bila Killip menurun maka LOS akan semakin pendek. Hasil tersebut dibuktikan dengan 50\% pasien STEMI dengan Killip I berada dalam kategori short LOS dan $50 \%$ pasien STEMI dengan Killip IV berada dalam kategori long LOS.

Killip menginterpretasikan adanya gagal jantung dimulai pada Killip II (Shiraishi et al., 2014). Gagal jantung terjadi jika kontraktilitas ventrikel kiri yang menurun dan meningkatkan volume residu ventrikel. Kelainan pada kerja ventrikel jantung ini mengakibatkan menurunnya curah jantung (PERKI, 2015). Perburukan prognosis pun meningkat seiring dengan tingginya derajat gagal jantung yang dimiliki oleh pasien STEMI. Dalam penelitian ini sebanyak $50 \%$ pasien STEMI pada Killip II memiliki LOS kurang dari 3 hari. Berdasarkan data tersebut didapatkan bahwa pada pasien STEMI dengan Killip II, dikarenakan memiliki gagal jantung tahap awal, prognosis yang dimiliki pun masih dalam kategori short LOS.

Pada Killip III bila gagal jantung terus berlanjut, maka bendungan akan terjadi dalam paru - paru yaitu terjadinya edema paru dengan segala keluhan dan tanda - tanda akibat adanya tekanan dalam sirkulasi yang meninggi (PERKI, 2015). Tekanan yang tinggi tersebut menyebabkan akumulasi cairan pada interstitial dan alveoli. Pasien STEMI dengan edema paru akan mengalami hipertensi, stenosis arteri ginjal, takikardi dan atrial fibrilasi (NIH, 2012). Dalam penelitian ini, pasien STEMI pada Killip III sebanyak $40 \%$ berada pada long LOS dan $40 \%$ pada medium LOS. Berdasarkan data diatas, $50 \%$ pasien STEMI dengan Killip III memiliki prognosis yang lebih buruk ditunjukkan dengan LOS diatas 5 hari dikarenakan selain memiliki gagal jantung, disertai juga dengan adanya edema paru.

Kategori Killip IV ialah pasien STEMI mengalami syok kardiogenik (PERKI, 2015). Syok kardiogenik merupakan komplikasi paling

\section{DAFTAR PUSTAKA}

Aissaoui N, Puymirat E, Simon T, et al. (2011). Long-term outcome in early survivors of cardiogenic shock at the acute stage ofmyocardial infarction: a landmark analysis from the French. Eur Heart $\mathrm{J}$; 32: 2999-3054. serius pada pasien STEMI. Syok kardiogenik, penggunaan agen vasopressor, umur, serangan jantung, gagal ginjal dan insersi balon telah terbukti sebagai prediktor prognosis perburukan yang independen pada kondisi klinis pasien STEMI di rumah sakit. Sebuah studi telah melaporkan 572 pasien STEMI dengan syok kardiogenik mengindikasikan aritmia dan profil klinis yang lebih parah (Cao et al., 2014). Dalam penelitian ini $50 \%$ pasien STEMI pada Killip IV memiliki kategori long LOS. Berdasarkan data diatas diketahui bahwa pasien STEMI dengan Killip IV memiliki prognosis yang buruk ditunjukkan dengan LOS lebih dari 5 hari.

Pada keadaan syok, hipoperfusi yang terjadi pada miokardium dan jaringan perifer akan mendorong terjadinya metabolisme anaerobik sehingga dapat menyebabkan asidosis laktat.Keadaan hiperlaktatemia ini dapatmengganggu fungsi miokardium. Akhir dari proses ini adalah kerusakan yang ireversibel pada miokard akibat iskemik (Hochman et al., 2009). Pada studi dengan follow up selama 5 tahun, pada 3670 pasien, syok kardiogenik pada tahap awal telah berhubungan dengan perburukan pada status klinis pasien STEMI selama 1 tahun (Aissaoui, 2014). Perburukan status klinis pasien STEMI hingga komplikasi mempengaruhi lama rawat pasien di rumah sakit, Killip menjadi salah satu prediktor yang penting untuk mengetahui prognosis tersebut selama 30 hari di ICCU (Wickramatilakeet al, 2015).

\section{KESIMPULAN}

Kesimpulan dalam penelitan ini adalah skor risiko Killip memiliki hubungan signifikan dengan LOS pasien STEMI di ICCU.

\section{SARAN}

Perlu dipertimbangkan dalam penggunaan prediktor Killip sebagai parameter dan perhitungan yang mudah dalam mendeteksi adanya perburukan pasien STEMI sehingga memudahkan pengambilan keputusan penatalaksanaan pasien. Perlu dilakukan penelitian lebih lanjut mengenai akurasi prediktor Killip dalam follow up setelah keluar rumah sakit dan ketika kontrol rutin ke poliklinik.

Cardiac Care Network. (2013). Management of acute coronary syndromes. Kori Kingsbury Chief Executive Officer Cardiac Care Network 416-512-7472

Chen, H., Lee, W., Chen, Y., Fang, H., Chen, C., Yang, C., . . . Wu, C. (2016). The 
impacts of prolonged emergency department length of stay on clinical outcomes of patients with ST-segment elevation myocardial infarction after reperfusion. Internal and Emergency Medicine, 11(1), 107-114. doi:http://dx.doi.org/10.1007/s11739-0151330-5

De Mello, B. H. G., Oliveira, G. B. F., Ramos, R. F., Lopes, B. B. C., Barros, C. B. S., Carvalho, E. de O., Piegas, L. S. (2014). Validation of the Killip-Kimball Classification and Late Mortality after Acute Myocardial Infarction. Arquivos Brasileiros de Cardiologia, 103(2), 107117. http://doi.org/10.5935/abc.20140091

Departemen Kesehatan RI.(2005).Standar Pelayanan Minimal. DirektoratJenderal Bina Kesehatan Masyarakat. Jakarta.

Depkes RI. (2013). Riset Kesehatan Dasar. Jakarta: Badan Penelitian dan pengembangan Kesehatan Kementrian Kesehatan RI.

F. Kaa, K.A. Eagle, J.M. Gore, P.G. Steg, F.A. Anderson, for the GRACe investigators. (2010). The global registry of acute coronary events, 1999 to 2009GRACEHeart, 96 , pp. 1095-1101

Granger CB, Goldberg RJ, Dabbous O, Pieper $K S$, Eagle KA, Cannon CP, Van de Werf F, Avezum Á, Goodman SG, Flather MD, Fox KAA. (2003). for the Global Registry of Acute Coronary Events Investigators. Predictors of Hospital Mortality in the Global Registry of Acute Coronary Events. Arch Intern Med.163(19):23452353.doi:10.1001/archinte.163.19.2345

Hou L, Gao C, Feng J, Chen ZF, Zhang J,et al. (2017). Prognostic Factors for In-Hospital and Long-Term Survival in Patients with Acute ST-Segment Elevation Myocardial Infarction after Percutaneous Coronary Intervention. Tohoku J. Exp. Med., 2017 May, 242 (1), 27-35
Meier P, Lansky AJ, Baumbach A. Almanac. (2013). Acute coronary syndromes. Heart.99:1488-1493.

Mendez et al. (2012). Comparison of the Prognostic Predictive Value of the TIMI, PAMI, CADILLAC, and GRACE Risk Scores in STEACS Undergoing Primary or Rescue PCl. Rev Esp Cardiol; 65(3):227233

National Institute for Health and Care Excellence. (2013). Myocardial infarction with ST-segment elevation: acute management. Clinical guideline Published: nice.org.uk/guidance/cg167

Nikus, K., Birnbaum, Y., Eskola, M., Scalrovsky, S., Zhong-qun, Z \& Pahlm, O (2014) Updated Electrocardiographic Classification of Acute Coronary Syndromes. Current Cardiology Reviews, 10, 229-236

WHO (2013). Cardiovascular risk factor trends and potential for reducing coronary heart disease mortality in the United States of Americahttp://www.who.int/bulletin/volume s/88/2/08-057885/en/.

Wickramatilake et al. (2015). Predictability of adverse clinical events following STelevation myocardial infarction by risk assessment tools. Galle Medical Journal, Vol 20.

Yildirim, Erkan, lyisoy, Atila, Celik, Murat, Yuksel, Uygar Cagdas, Acikel, Cengizhan, Bugan, Baris, \& Gokoglan, Yalcin. (2017). The Relationship Between Gensini Score and In-Hospital Mortality in Patients with ST-Segment Elevation Myocardial Infarction. International Journal of Cardiovascular Sciences, 30(1), 32-41. https://dx.doi.org/10.5935/23594802.20170017 